\title{
REPORT: VISIT TO CALIFORNIA STATE UNIVERSITY: LOS ANGELES AND DOMINQUEZ HILLS CAMPUSES: 1-7 AUGUST 1999
}

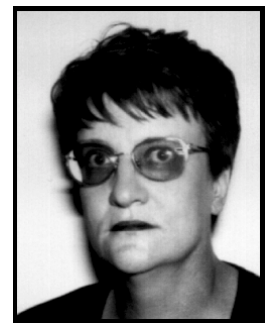

\section{OVERVIEW OF THE CALIFORNIA STATE UNIVERSITY (CSU)}

According to the California State University's (CSU's) Chancellor, Professor CB Reed, the CSU is America's largest senior system of higher education with 350000 students on 22 campuses, situated throughout California. The University of California was founded in 1947 and celebrated its fiftieth anniversary during 1997. However, the oldest campus, the San Jose State University, was founded in 1857 and the most recently opened campus at Monterey Bay, started admitting students only during 1995. The Academic Senate of the California State University, is composed of elected representatives of the faculty from each campus, and recommends academic policy to the Board of Trustees through the Chancellor.

Admission standards are strict, complying with or exceeding the minimum specifications of the California State. Besides specific school subjects and school grades, prospective students also need to be tested in English and in Mathematics prior to enrolment to determine their eligibility for specific courses. All foreign students need to obtain satisfactory pass marks in the Test of English as a Foreign Language (TOEFL) - different campuses have different minimum acceptable grades. Furthermore, students are required to present proof of immunisations against measles and rubella at the beginning of their second term of enrolment.

The 1999-2000 annual enrolment costs per undergraduate student at this State University amounted to US\$ 1506 , if registered for six or more units, and to US\$ 1584 per postgraduate student.

Most classes are offered on site but an ever-increasing number of courses become available for students wishing to pursue distance education courses, comprising video conferencing and Internet courses. Many students combine some distance education courses with full time and/or part time courses. The different campuses specialise in specific courses to some extent, necessitating some students to relocate in order to obtain specific qualifications. Each campus is entitled to limit the number of students who can register annually, and to accept only limited numbers of students majoring in specific courses at specific campuses in any year. Once the maximum number of students for a specific major has been admitted, the course becomes "impacted" at that campus and further students will be redirected to other campuses or to other major subjects. Some campuses also offer so-called "Open University Classes" permitting members of the general community to follow regular university courses without going through the formal admission processes provided space is available in the specific course during a specific term or semester. Students following Open University Classes can update their professional knowledge, earn continuing education credit units subject to specifications, and earn a limited number of credits toward obtaining a degree.

In addition to the normal courses offered throughout the academic year, selected courses are also offered at specific campuses during the summer 
holidays (May-August) to assist students to enhance their skills in specific courses, especially languages, or to accelerate their progress by completing one or more courses during the summer holidays.

The campuses visited included the Los Angeles (UCLA) campus with 19160 students and the

Dominguez Hills campus (UCDH) with 10704 students. The CSU's World Wide Web home page, providing detailed information about courses, programmes and registration procedures, can be accessed at: http://www.calstate.edu (California State University, 1999-2000:3-11).

\section{VISIT: THE UNIVERSITY OF CALIFOR-} NIA, LOS ANGELES (UCLA) CAMPUS

\section{Department of Nursing}

Visits were co-ordinated by Professor Marlene Farrell, from the Nursing Faculty, UCLA. The Faculty of Nursing falls within the School of Health and Human Services at the UCLA campus.

Discussions were held with the Chairperson, Professor Judith Papenhausen, and staff of the Department of Nursing, UCLA. Identified challenges included coping with the increasing number of under- and postgraduate students whilst the number of academic staff members continues to decline. During 1999 the Department of Nursing coped by offering contract appointments to retired staff members, and by offering practising nurses part-time teaching positions. Specific programmes were offered on-site, such as in a hospital in Santa Barbara, but then the services requesting specific programmes, financed the Faculty's expenditures for these specific courses.

This Department of Nursing offers a Bachelor of Science Degree in Nursing (BSN) and a Master of Science Degree in Nursing (MSN).
The purpose of UCLA's BSN nursing programme is stated as:

"The Bachelor of Science Degree in Nursing is an upper division program especially designed for registered nurses who have completed the lower division nursing courses at community colleges or hospital schools of nursing. Full time students can complete the program in six quarters" (California State University, Los Angeles, 1999a). Only candidates with California Registered Nurse licenses, valid California drivers' licenses, with no grade lower than a "C" for any nursing course can be admitted to the BSN (Bachelor of Science Degree in Nursing). The BSN is accredited by the California Board of Registered Nursing and by the National League of Nursing (NLN).

Students registering for the MSN degree should be in possession of a BSN degree and meet the minimum academic achievements (minimum B or 3.0 grade point average in upper division nursing courses), and have completed courses in both statistics and nursing research within the past seven years. The MSN is accredited by the NLN. The MSN provides advanced study and specialisation in administration, education, nurse case management, clinical nurse specialisation in psychiatric mental health, and nurse practitioner (with options for specialising in adult care, paediatrics, acute cardio-pulmonary care for adults, critical care for children).

Associate degree nurses wishing to pursue the MSN courses can follow one of two accelerated tracks: those with non-nursing bachelor's degrees . those without any bachelor's degrees.

Basically the accelerated tracks imply that the students need to complete the courses missing for the BSN whilst they pursue their MSN courses. Credits can be granted subject to specifications. However, to remain in the accelerated courses, the MSN students need to maintain a minimum average $B$ grade point in upper division nursing courses. 
At this Faculty of Nursing, MSN students complete their Nursing Research courses during the last part of their programmes, because the lecturers consider them to derive maximum benefit from these research courses at the end of their MSN programmes. Students are not compelled to generate research, but to criticise and utilise research, by focusing on mid-range theories. MSN students are required to evaluate research reports, criticise the research methodology used, including qualitative research approaches.

Although all the lecturers at the Faculty of Nursing held doctorates, this Faculty did not offer doctoral programmes for nurses, because the demands of such a programme would exceed the capabilities of the available staff members. Prospective doctoral candidates were referred to the University of California, San Francisco (UCSF) or to the Texas Women's University offering a summers-only doctoral programme enabling students to maintain their full time teaching or other jobs in Los Angeles, whilst pursuing part-time doctoral studies in another state.

\section{Center for Effective Teaching and Learning}

One day was spent with Professor George Taylor in the Center for Effective Teaching and Learning. Professor Taylor and his colleagues specialise in teaching staff and students computer skills, including how to design home pages on the Internet.

The Center for Distance Learning was visited. A course in Fire Protection Administration and Technology, was being videotaped whilst the lecturer presented the contents to a class of students at the UCLA campus. Simultaneously a class of students in San Francisco participated by means of video conference facilities. Students who could not attend class, could watch the video tapes at specific times, and this would be recorded on their student activity files.

Further information about Distance Learning courses offered by UCLA can be obtained from the following website: http://www.calstatela.edu/ cont_ed. More information about continuing education courses can be located at: http.// bestla.calstatela.edu/www/lifelong/learning.html

Two courses offered entirely on-line which attracted much attention and numerous debates from many countries were:

The Math Prep Course preparing candidates for the Entry Level Mathematics Examination, comprising algebra, data interpretation and geometry, is completely on-line requiring no campus visits and no prescribed books (more information available from: www.elmprep.com/la.html).

Music librarianship presented entirely via the World Wide Web and e-mail which familiarises librarians with the special needs for music librarianship, including cataloging of sheet music, multi-media, audio- and video recordings (more information available from www.calstatela.edu/ staff/nweckwe/mflyer.htm or by e-mailing: nweckwe@ calstatela.edu).

\section{VISIT: THE UNIVERSITY OF CALIFOR- NIA, DOMINGUEZ HILLS (UCDH)}

\section{Visits to clinics offering clinical experiences to students}

Clinics operated by nurses, with the telephonic assistance of medical practitioners, were visited in Pasadena North and in Cudaby. These clinics provide practical experience to nursing students from the University of California, Dominguez Hills (UCDH) campus. Many of these clinics' nurse practitioners also lectured part time at the UCDH. The large numbers of volunteers, including students and school children, who worked at these clinics as cleaners, clerks, typists, and even nurse auxiliaries created lasting impressions of community involvement in clinical activities. During discussions 
with two schoolgirls, sacrificing their final summer school holiday to work at a clinic, it became apparent that their chances of obtaining scholarships for nursing courses could be considerably enlarged by their hours of voluntary community service accumulated over a number of years.

Another interesting observation at the clinics was the obvious lack of contraception education. This appeared to be contradictory to the communities' needs, where large numbers of school girls were observed pushing babies into school areas where their babies attended day care facilities whilst the adolescent mothers continued with their school lessons. When questioned, the students explained that the majority of people living in the areas surrounding the clinics belonged to the Roman Catholic faith and that contraceptives were not freely discussed, but advice would be given should any person request it.

\section{The Division of Nursing, School of Health, Dominguez Hills (UCDH)}

At the Dominguez Hills Campus, the Division of Nursing falls within the School of Health. The BSN and MSN programmes offered are similar to those offered at the Los Angeles campus except that MSN students can specialise in the following options:

- Nurse Education

- Nurse Administration

- Parent-Child Clinical Nurse Specialist

- Gerontology Clinical Nurse Specialist

- Family Nurse Practitioner.

Both the BSN and the MSN are accredited by the National League of Nursing. During 1999 more than 3000 students were enrolled in these nursing programmes.

This Division of Nursing commenced offering statewide BSN and MSN programmes during 1981 with the mission to:

make quality higher education in nursing more accessible to employed registered nurses

- ultimately improve health care in California.

Initially the BSN and MSN programmes were funded by the WK Kellogg Foundation, health care organisations and individuals. In order to reach nurses who cannot pursue advanced nursing studies because of geographical constraints, the Division of Nursing co-operates with a private agency to offer courses and degree programmes through electronic media - satellite delivery, cable vision, computer conferencing/e-mail, voice mail, and video tapes. This Division of Nursing has divided the entire State of California into specific regions, with a student advisor for each region. This student advisor visits selected health care services at predetermined times to inform prospective students about the available courses, regulations and distance education possibilities. Prospective as well as registered students are encouraged to maintain regular contact with their specific student advisors.

\section{The Center for International Nursing Edu- cation (CINE)}

Based on the successes of the Dominguez Hills' Campus Statewide Nursing Program, requests accumulated to establish a Centre for International Nursing Education (CINE). With the assistance of WK Kellogg grants, this center was established in 1990, with the aim of assisting the international community in improving and expanding educational opportunities for health care professionals. It has provided services to governments, national organisations, public and private health care agencies and universities in Europe, Africa, Asia and Latin America.

Prof. Judith Lewis, the Head of CINE, explained that the major functions of CINE include:

US Preparation Programme for foreign nurses, providing a background in US nurs 
ing and health care in strengthening language and academic skills prior to commencing studies at US universities;

visiting Scholars' Programme designed for individual students and based on their specific needs varying in duration from one month to one year;

continuing Education Programmes enabling professionals to update and expand their knowledge without enrolling in formal degree programmes;

- workshops and seminars tailored to clients' needs; and

- programmes for Departments of Nursing at universities in Mexico, Brazil, Chile, Columbia and other Latin American countries. The activities in these countries do not imply transplanting Californian programmes to other countries, but strive to build in-country capacities with regard to specific aspects, such as curriculum design. These programmes are offered at invitation from the country and the university concerned and can be offered in English, Spanish or Portuguese by CINE staff members.

More information about CINE's activities and programmes can be obtained from the following email address: cine@csudh.edu.

\section{ACKNOWLEDGEMENTS}

I wish to express my sincere gratitude to Unisa's Research and Bursaries Committee for awarding me a travel grant and for granting me leave to make the above visit possible. All the persons who helped to make this visit a reality, and especially the staff at UCLA and at UCDH, whether mentioned in the report or not, who sacrificed some of their precious time to accommodate my requests, and to engage in discussions and visits, need to be acknowledged specifically, with special reference to Proff. Marlene Farrell, Judith Lewis, Judith
Papenhausen and George Taylor.

\section{REFERENCES}

California State University, Los Angeles 1999a: Bachelor of Science Degree in Nursing (Information Brochure).

California State University, Los Angeles 1999b: Master of Science Degree in Nursing (Information Brochure).

California State University 1999-2000: Summer 1999Spring 2000 Undergraduate Admission (Information Brochure).

California State University, Dominguez Hills 1999-2000: University Catalog. 